\title{
Alkaline organosolv pretreatment of different sorghum stem parts for enhancing the total reducing sugar yields and $p$-coumaric acid release
}

\author{
Dandan Li, Liangkun Long and Shaojun Ding ${ }^{*}$ (i)
}

\begin{abstract}
Background: The sorghum stem can be divided into the pith and rind parts with obvious differences in cell type and chemical composition, thus arising the different recalcitrance to enzyme hydrolysis and demand for different pretreatment conditions. The introduction of organic solvents in the pretreatment can reduce over-degradation of cellulose and hemicellulose, but significance of organic solvent addition in pretreatment of different parts of sorghum stem is still unclear. Valorization of each component is critical for economy of sorghum biorefinery. Therefore, in this study, $\mathrm{NaOH}$-ethanol pretreatment condition for different parts of the sorghum stem was optimized to maximize $p$-coumaric acid release and total reducing sugar recovery.

Result: Ethanol addition improved $p$-coumaric acid release and delignification efficiency, but significantly reduced hemicellulose deconstruction in $\mathrm{NaOH}$-ethanol pretreatment. Optimization using the response surface methodology revealed that the pith, rind and whole stem require different $\mathrm{NaOH}$-ethanol pretreatment conditions for maximal $p$-coumaric acid release and xylan preservation. By respective optimal $\mathrm{NaOH}$-ethanol pretreatment, the $p$-coumaric acid release yields reached $94.07 \%, 97.24 \%$ and $95.05 \%$ from pith, rind and whole stem, which increased by $8.16 \%$, 8.38\% and 8.39\% compared to those of $\mathrm{NaOH}$-pretreated samples. The xylan recoveries of pith, rind and whole stem reached $76.80 \%, 88.46 \%$ and $85.01 \%$, respectively, which increased by $47.75 \%, 15.11 \%$ and $35.97 \%$ compared to $\mathrm{NaOH}$ pretreatment. Adding xylanase significantly enhanced the enzymatic saccharification of pretreated residues. The total reducing sugar yields after respective optimal $\mathrm{NaOH}$-ethanol pretreatment and enzymatic hydrolysis reached 84.06\%, $82.29 \%$ and $84.09 \%$ for pith, rind and whole stem, respectively, which increased by $29.56 \%, 23.67 \%$ and $25.56 \%$ compared to those of $\mathrm{NaOH}$-pretreated samples. Considering the separation cost of the different stem parts, whole sorghum stem can be directly used as feedstock in industrial biorefinery.

Conclusion: These results indicated that $\mathrm{NaOH}$-ethanol is effective for the efficient fractionation and pretreatment of sorghum biomass. This work will help to understand the differences of different parts of sorghum stem under $\mathrm{NaOH}$-ethanol pretreatment, thereby improving the full-component utilization of sorghum stem.
\end{abstract}

Keywords: Sorghum stem, $\mathrm{NaOH}$-ethanol pretreatment, $p$-Coumaric acid, Enzymatic hydrolysis

*Correspondence: dshaojun@hotmail.com; dshaojun@njfu.edu.cn The Co-innovation Center of Efficient Processing and Utilization of Forest Resources, Jiangsu Key Lab for the Chemistry \& Utilization of Agricultural and Forest Biomass, College of Chemical Engineering, Nanjing Forestry University, Nanjing, China

\section{Background}

Lignocellulosic biomass is an important feedstock for the production of biofuels and biochemicals [1]. Cellulose, hemicellulose and lignin are the main biochemical components of lignocellulose. These three components are 
strongly intermeshing and bonded together (covalently or non-covalently) to form lignocellulosic matrix. Structural features make lignocellulosic biomass difficult to be deconstructed and digested, and result in relatively low utilization of lignocellulosic feedstock [2]. To improve the enzymatic digestibility of lignocellulosic biomass, various pretreatment methods have been investigated based on the properties of each lignocellulosic feedstock [3]. Common pretreatment methods include acid treatment, alkali treatment, organosolv treatment, automated hydrolysis treatment, steam explosion treatment, etc. [4]. Among these pretreatment methods, alkali pretreatment is widely used due to the advantages of non-corrosive, non-toxic, and efficient delignification $[5,6]$. $\mathrm{NaOH}$ pretreatment is one of leading technologies for pilot-scale biorefinery of herbaceous lignocellulose [7]. However, in traditional $\mathrm{NaOH}$ pretreatment, half or even more amount of the hemicellulose is also dissolved in black liquor $[8,9]$.

In general, the purpose of the pretreatment is to remove lignin and hemicellulose, thereby increasing the enzymatic hydrolysis efficiency of cellulose [10]. Xylan is the main hemicellulose component occupying 20-30\% of biomass of the hardwoods (dicots) and herbaceous plants [11]. Effective utilization of xylan can improve the rational utilization of sugars in lignocellulosic biomass, which leads to the production of high-yield fermentable sugar/ethanol [12, 13]. However, xylan is susceptible to alkali pretreatment processes and easier to be degraded than cellulose due to its amorphous and branched structure [14]. The dissolved xylan in the liquid streams was partially destroyed and it was difficult to be fully recovered and reutilized [15], therefore reducing the total sugar utilization. The use of organic solvents (such as ethanol) instead of water during alkaline pretreatment avoids the over-deconstruction of cellulose and hemicellulose, as well as the formation of conventional inhibitors [16].

Sorghum is one of the main bioenergy crops, and the biorefinery of its soluble sugar and bagasse residue for biofuels and biochemicals has attracted much attention in recent years [17-20]. Beside soluble sugar and lignocellulose residue, sorghum stem also contains significant amounts of hydroxycinnamic acid, such as $p$-coumaric acid ( $p$ CA, up to $35 \mathrm{mg} / \mathrm{g}$ cell walls), which is far higher than other agricultural waste biomass such as rice straw $(6.8 \mathrm{mg} / \mathrm{g}$ cell walls) $[21,22] . p C A$ is widely used in the health and pharmaceutical industries because of a variety of physiological functions such as anti-inflammatory, antineoplastic, and antimicrobial activities [23]. Its phenolic acid structure can eliminate free radicals in the body and has a preventive effect on diseases closely related to oxidative stress damage [24]. $p \mathrm{CA}$ is also a precursor for the production of value-added aromatic chemical products [25]. In lignocellulose, $p C A$ is attached to lignin via an ester linkage [26]. The ester bond can be broken under mild alkaline conditions, so mild alkali treatment was often used for extraction of $p$ CA and more than $90 \%$ of $p C A$ can be released from agricultural residues $[8,22]$.

Previous studies have reported the recalcitrance to enzymatic digestion in different parts of internodes from sugar cane due to cell type and chemical composition [27]. The sugar cane pith region contained parenchyma cells that were not extensively lignified. In contrast, the rind region contained highly lignified vessels and fibers and was very recalcitrant to enzymatic hydrolysis [27]. Similar trend was observed in sorghum stem. The sorghum stem parts can be divided into inner region and rind part, which have different lignin content, hydroxycinnamic acid content and carbohydrate composition [21]. Although it was frequently reported that organic solvent-assisted alkaline pretreatment can reduce overdegradation of cellulose and hemicelluloses [16, 28], the significance of organic solvent addition in $\mathrm{NaOH}$ pretreatment of different stem parts of sorghum is still unclear. In this study, $\mathrm{NaOH}$-ethanol pretreatment was described to facilitate the release of $p C A$ in different parts of sorghum stem, but minimize the degradation of sugar polymers (cellulose and hemicellulose) as much as possible, and therefore enhance the total reducing sugar recovery. The processing conditions $(\mathrm{NaOH}$ loading, ethanol content, processing time and temperature) were optimized using response surface methodology. Structural characterizations of raw and pretreated sorghum sample were investigated by Fourier transform infrared (FTIR) spectroscopy, scanning electron microscopy (SEM) and X-ray diffraction (XRD).

\section{Results and discussion}

\section{Composition of raw sorghum samples}

The composition of raw pith, rind and whole stem on a dry matter basis is shown in Table 1 . The content of esterified $p C A$ in pith was $2.21 \%$, which was slightly higher than that in rind (2.08\%). The content of cellulose $(40.64 \%)$ and lignin $(24.04 \%)$ in rind was slightly higher than that in pith $(37.20 \%$ and $21.48 \%$, respectively), while the xylan content of the rind $(17.33 \%)$ was slightly lower than that of the pith (18.51\%). The total carbohydrates including glucan, xylan, and arabinan in rind and pith reached $60.29 \%$ and $58.25 \%$, respectively. It was worth noting that other components such as ash, extractives and lower content of sugars also exist in sorghum stems according to previous report [29], despite these constituents were not analyzed in this study. Variations in sorghum stem composition from previous researches were observed in this study, which may be due to the 
Table 1 Composition of raw sorghum pith, rind and the whole stem

\begin{tabular}{lllllll}
\hline & Glucan (\%) & Xylan (\%) & Arabinan (\%) & Lignin (\%) & Ester-linked $p$ CA (\%) & $\begin{array}{c}\text { Ester-linked } \\
\text { ferulic acid } \\
\text { (\%) }\end{array}$ \\
\hline Pith & $37.20 \pm 0.19$ & $18.51 \pm 0.10$ & $2.54 \pm 0.06$ & $21.48 \pm 0.23$ & $2.21 \pm 0.14$ & $0.38 \pm 0.07$ \\
Rind & $40.64 \pm 0.08$ & $17.33 \pm 0.13$ & $2.32 \pm 0.11$ & $24.04 \pm 0.27$ & $2.08 \pm 0.22$ & $0.43 \pm 0.04$ \\
Whole stem & $38.22 \pm 0.21$ & $17.70 \pm 0.07$ & $2.47 \pm 0.09$ & $23.35 \pm 0.31$ & $2.13 \pm 0.17$ & $0.41 \pm 0.09$ \\
\hline
\end{tabular}

differences in the geographical location, fertilization, heterogeneity of feedstock of the samples and several other environmental factors $[8,29]$.

\section{Comparison of $\mathrm{NaOH}$-ethanol pretreatment of different sorghum stem parts}

Box-Behnken models were designed to optimize various process parameters $(\mathrm{NaOH}$ loading $\mathrm{A}$, ethanol content $\mathrm{B}$, temperature $\mathrm{C}$ and time $\mathrm{D}$ ) in $\mathrm{NaOH}$-ethanol pretreatment of different sorghum stem parts. The following equations were derived for the analysis of the release of $p C A$ and the recovery of xylan in residues.

Pith

$$
\begin{aligned}
p \text { CA release yield }(\%)= & +79.99+27.46 \mathrm{~A}+7.01 \mathrm{~B}+4.73 \mathrm{C} \\
& +5.32 \mathrm{D}+1.63 \mathrm{AB}-4.27 \mathrm{AC} \\
& +2.71 \mathrm{AD}+1.70 \mathrm{BC}-7.82 \mathrm{BD} \\
& -1.13 \mathrm{CD}-15.69 \mathrm{~A}^{2}-2.98 \mathrm{~B}^{2} \\
& -3.00 \mathrm{C}^{2}-0.99 \mathrm{D}^{2}
\end{aligned}
$$

Xylan recovery yield (\%)

$$
\begin{aligned}
= & +80.39-9.88 \mathrm{~A}+3.26 \mathrm{~B}-0.35 \mathrm{C}-0.4392 \mathrm{D} \\
& -0.54 \mathrm{AB}+1.11 \mathrm{AC}-0.95 \mathrm{AD}-2.83 \mathrm{BC} \\
& +4.83 \mathrm{BD}+2.48 \mathrm{CD}-3.13 \mathrm{~A}^{2}-1.23 \mathrm{~B}^{2} \\
& -2.51 \mathrm{C}^{2}-2.40 \mathrm{D}^{2}
\end{aligned}
$$

Rind

$$
\begin{aligned}
& p \text { CA release yield (\%) } \\
& =+85.52+33.62 \mathrm{~A}+6.54 \mathrm{~B}+3.57 \mathrm{C} \\
& +7.38 \mathrm{D}+5.03 \mathrm{AB}-0.57 \mathrm{AC}-1.27 \mathrm{AD} \\
& -0.59 \mathrm{BC}-7.92 \mathrm{BD}-1.83 \mathrm{CD}-22.48 \mathrm{~A}^{2} \\
& -5.14 \mathrm{~B}^{2}-4.22 \mathrm{C}^{2}-2.50 \mathrm{D}^{2}
\end{aligned}
$$

$$
\begin{aligned}
& \text { Xylan recovery yield }(\%) \\
& \begin{aligned}
= & +81.24-3.51 \mathrm{~A}+4.33 \mathrm{~B}-0.5442 \mathrm{C} \\
& -1.56 \mathrm{D}+3.00 \mathrm{AB}-0.9225 \mathrm{AC}-0.07 \mathrm{AD} \\
& +0.945 \mathrm{BC}-1.93 \mathrm{BD}-0.41 \mathrm{CD}
\end{aligned}
\end{aligned}
$$

Whole stem

$$
\begin{aligned}
& p \text { CA release yield }(\%) \\
& =+82.06+28.92 \mathrm{~A}+6.67 \mathrm{~B}+4.79 \mathrm{C} \\
& +5.44 \mathrm{D}+2.93 \mathrm{AB}-4.34 \mathrm{AC}+1.12 \mathrm{AD} \\
& +0.4875 \mathrm{BC}-7.45 \mathrm{BD}+0.93 \mathrm{CD}-16.88 \mathrm{~A}^{2} \\
& \quad-3.46 \mathrm{~B}^{2}-2.45 \mathrm{C}^{2}-1.24 \mathrm{D}^{2}
\end{aligned}
$$

Xylan recovery yield (\%)

$$
\begin{aligned}
= & +80.39-7.23 \mathrm{~A}+4.27 \mathrm{~B}-0.1708 \mathrm{C} \\
& -0.56 \mathrm{D}-1.96 \mathrm{AB}+1.65 \mathrm{AC}-0.32 \mathrm{AD} \\
& +2.14 \mathrm{BC}-1.68 \mathrm{BD}-1.69 \mathrm{CD}-5.08 \mathrm{~A}^{2} \\
& -1.20 \mathrm{~B}^{2}+0.338 \mathrm{C}^{2}-0.5143 \mathrm{D}^{2}
\end{aligned}
$$

The effect of different variables on the release of $p \mathrm{CA}$ and the recovery of xylan in residues from different sorghum parts were investigated. Overall, $\mathrm{NaOH}$ concentration and ethanol content were the first and second most influential factors on the $p$ CA release yield and xylan recovery yield, respectively. As shown in Table 2, the released contents of $p \mathrm{CA}$ from the sorghum stem were strongly depended on the $\mathrm{NaOH}$ concentration; however, some variation existed among different stem parts. At a low $\mathrm{NaOH}$ concentration (i.e., 0.5\%), the release of $p \mathrm{CA}$ was very low, but significantly higher $p C A$ was released from the pith than from the rind under the same conditions. As the $\mathrm{NaOH}$ concentration increased and the ethanol content exceeded $40 \%(\mathrm{v} / \mathrm{v})$, the release of $p \mathrm{CA}$ from the rind slightly exceeded over that from the pith under the same conditions. $\mathrm{NaOH}$ concentration is also the key factor affecting the xylan dissolution, and more xylan was dissolved as $\mathrm{NaOH}$ concentration increased. In general, xylan was more resistant to be dissolved from the rind than from the pith in the same $\mathrm{NaOH}$-ethanol conditions. 
Table 2 Factors ( $\mathrm{NaOH}$ loading, ethanol content, temperature, and time) and the responses (released $p \mathrm{CA}$ and recovered xylan in residues) of the Box-Behnken design used for response surface methodology

\begin{tabular}{|c|c|c|c|c|c|c|c|c|c|c|}
\hline \multirow[t]{3}{*}{ Run } & \multicolumn{4}{|l|}{ Factor } & \multicolumn{6}{|c|}{ Response } \\
\hline & \multirow[t]{2}{*}{$\mathrm{NaOH}(\%)$} & \multirow[t]{2}{*}{ Ethanol (\%) } & \multirow[t]{2}{*}{ Temperature $\left({ }^{\circ} \mathrm{C}\right)$} & \multirow[t]{2}{*}{ Time (h) } & \multicolumn{3}{|c|}{ Released $p C A(\%)$} & \multicolumn{3}{|c|}{$\begin{array}{l}\text { Recovered xylan in residues } \\
(\%)\end{array}$} \\
\hline & & & & & Pith & Rind & Whole & Pith & Rind & Whole \\
\hline 1 & 1.25 & 10 & 70 & 2.5 & 66.23 & 67.64 & 67.57 & 79.78 & 74.35 & 75.21 \\
\hline 2 & 1.25 & 70 & 65 & 1 & 83.99 & 83.74 & 83.82 & 76.06 & 86.71 & 84.69 \\
\hline 3 & 1.25 & 40 & 65 & 2.5 & 79.66 & 85.56 & 81.68 & 80.42 & 82.21 & 80.28 \\
\hline 4 & 2 & 10 & 65 & 2.5 & 85.05 & 88.45 & 88.29 & 63.95 & 72.78 & 62.18 \\
\hline 5 & 1.25 & 40 & 60 & 4 & 79.22 & 86.40 & 79.70 & 73.22 & 81.10 & 82.49 \\
\hline 6 & 1.25 & 10 & 65 & 4 & 84.90 & 87.36 & 87.19 & 65.39 & 77.34 & 77.80 \\
\hline 7 & 1.25 & 70 & 60 & 2.5 & 75.00 & 82.14 & 78.72 & 81.84 & 84.69 & 79.63 \\
\hline 8 & 2 & 40 & 65 & 1 & 85.44 & 88.31 & 87.60 & 65.11 & 80.53 & 70.17 \\
\hline 9 & 0.5 & 40 & 70 & 2.5 & 45.47 & 25.97 & 45.02 & 79.98 & 82.44 & 81.01 \\
\hline 10 & 0.5 & 40 & 65 & 4 & 32.36 & 31.59 & 33.02 & 89.17 & 82.95 & 80.13 \\
\hline 11 & 1.25 & 40 & 65 & 2.5 & 80.27 & 84.54 & 82.89 & 81.03 & 82.07 & 81.02 \\
\hline 12 & 0.5 & 70 & 65 & 2.5 & 36.49 & 21.49 & 32.92 & 88.92 & 85.44 & 88.17 \\
\hline 13 & 2 & 40 & 60 & 2.5 & 86.89 & 92.30 & 90.52 & 64.88 & 79.12 & 68.76 \\
\hline 14 & 1.25 & 70 & 65 & 4 & 84.15 & 86.52 & 85.85 & 83.71 & 82.64 & 81.43 \\
\hline 15 & 0.5 & 10 & 65 & 2.5 & 33.08 & 32.00 & 34.48 & 82.73 & 85.31 & 73.70 \\
\hline 16 & 1.25 & 70 & 70 & 2.5 & 90.14 & 91.14 & 90.73 & 79.94 & 86.96 & 87.58 \\
\hline 17 & 1.25 & 40 & 65 & 2.5 & 78.96 & 84.25 & 82.47 & 80.76 & 83.11 & 79.87 \\
\hline 18 & 0.5 & 40 & 65 & 1 & 31.53 & 19.42 & 29.79 & 85.12 & 89.10 & 83.22 \\
\hline 19 & 2 & 40 & 70 & 2.5 & 87.14 & 93.68 & 90.17 & 64.70 & 74.80 & 70.11 \\
\hline 20 & 2 & 70 & 65 & 2.5 & 94.97 & 98.07 & 98.44 & 67.98 & 84.89 & 68.77 \\
\hline 21 & 1.25 & 40 & 65 & 2.5 & 79.28 & 87.44 & 80.13 & 79.82 & 82.89 & 80.05 \\
\hline 22 & 1.25 & 10 & 60 & 2.5 & 57.88 & 56.28 & 57.51 & 70.35 & 75.86 & 75.80 \\
\hline 23 & 1.25 & 40 & 60 & 1 & 67.08 & 66.70 & 71.29 & 80.95 & 83.15 & 78.85 \\
\hline 24 & 0.5 & 40 & 60 & 2.5 & 28.14 & 22.31 & 28.02 & 84.60 & 83.07 & 86.24 \\
\hline 25 & 1.25 & 10 & 65 & 1 & 53.48 & 52.89 & 55.36 & 77.08 & 73.69 & 74.36 \\
\hline 26 & 1.25 & 40 & 65 & 2.5 & 81.77 & 85.79 & 83.11 & 79.91 & 82.58 & 80.74 \\
\hline 27 & 1.25 & 40 & 70 & 4 & 84.80 & 91.44 & 90.94 & 74.72 & 79.11 & 76.34 \\
\hline 28 & 1.25 & 40 & 70 & 1 & 77.19 & 79.06 & 78.81 & 72.52 & 82.80 & 79.47 \\
\hline 29 & 2 & 40 & 65 & 4 & 97.12 & 95.41 & 95.30 & 65.36 & 74.10 & 65.80 \\
\hline
\end{tabular}

This may be related to the difference in cell types and chemical composition in different sorghum stem parts. The pith is rich in parenchyma cells and the rind contains more vascular bundles. Parenchyma cells in pith have bigger lumens and thinner cell walls, and vascular bundles in rind are composed of tightly packed vessel elements [30]. On other hand, the easier dissolution of xylan from pith than those from rind under the same conditions may be partly attributed to the lower lignin content in the sorghum pith than in the rind [27]. Interestingly, there was a low linear correlation between the release of $p C A$ and the recovery of xylan in residues for both pith and rind (Additional file 1: Fig. S1). Indeed, there is little chemically structural connection between $p C A$ and xylan as most of $p C A$ is attached to lignin with ester bond [31].

The regression coefficients of the model were determined by analysis of variance (ANOVA) in Additional file 1: Table S1. All models were significant at the $P<0.0001$ level, which shows that all models were valid and do not lack fit, so this indicates that the model can be used to predict response. Several optimized solutions for model prediction were selected based upon the constraints: maximum xylan recovery in residues from different sorghum stem parts with the prerequisite of approximately 95\% $p$ CA release yield (not maximized). As shown in Table 3, the actual value was close to predicted value, which verified the reliability of the model. 
Table 3 Confirmation of the predicted optimum condition with the experimental results

\begin{tabular}{|c|c|c|c|c|c|c|c|}
\hline \multirow[t]{2}{*}{$\mathrm{NaOH}(\%)$} & \multirow[t]{2}{*}{ Ethanol (\%) } & \multirow{2}{*}{$\begin{array}{l}\text { Temperature } \\
\left({ }^{\circ} \mathrm{C}\right)\end{array}$} & \multirow[t]{2}{*}{ Time (h) } & \multicolumn{2}{|l|}{ Released $p C A(\%)$} & \multicolumn{2}{|c|}{ Recovered xylan in residues (\%) } \\
\hline & & & & Predicted values & Actual values & Predicted values & Actual values \\
\hline \multicolumn{8}{|l|}{ Pith } \\
\hline 1.63 & 70 & 66.0 & 3.18 & 94.59 & 94.07 & 77.28 & 76.85 \\
\hline 1.72 & 70 & 63.4 & 2.29 & 94.00 & 94.22 & 76.20 & 76.01 \\
\hline 1.51 & 70 & 65.2 & 3.30 & 92.63 & 91.76 & 77.69 & 76.32 \\
\hline \multicolumn{8}{|l|}{ Rind } \\
\hline 1.90 & 70 & 69.8 & 1.00 & 98.99 & 97.24 & 88.73 & 88.46 \\
\hline 1.80 & 70 & 62.1 & 1.50 & 97.28 & 97.05 & 87.56 & 86.47 \\
\hline 1.55 & 70 & 68.8 & 1.95 & 96.00 & 94.74 & 86.79 & 84.99 \\
\hline \multicolumn{8}{|l|}{ Whole stem } \\
\hline 1.46 & 70 & 70.0 & 2.19 & 95.13 & 95.05 & 85.35 & 85.04 \\
\hline 1.52 & 70 & 70.0 & 2.00 & 95.90 & 94.77 & 83.68 & 82.96 \\
\hline 1.39 & 70 & 70.0 & 3.00 & 92.07 & 92.31 & 82.85 & 82.12 \\
\hline
\end{tabular}

Compared with pith, the $\mathrm{NaOH}$ concentration in rind was higher, and the treatment time was shorter. The possible reason is that the structure of the rind is denser, so higher $\mathrm{NaOH}$ concentration was needed to release $p \mathrm{CA}$, and in turn shortening the processing time.

According to the above optimization using response surface methodology, the following conditions were selected for $\mathrm{NaOH}$-ethanol pretreatment to obtain the maximum release of $p \mathrm{CA}$ and the maximum recovery of xylan in residues for the pith, rind and whole stem in further experiments: $1.63 \% \mathrm{NaOH}, 70 \%$ ethanol, $66{ }^{\circ} \mathrm{C}$, $3.18 \mathrm{~h} ; 1.90 \% \mathrm{NaOH}, 70 \%$ ethanol, $69.8{ }^{\circ} \mathrm{C}, 1.00 \mathrm{~h}$ and $1.46 \% \mathrm{NaOH}, 70 \%$ ethanol, $70{ }^{\circ} \mathrm{C}, 2.19 \mathrm{~h}$, respectively. $\mathrm{NaOH}$ pretreatment was also carried out in same conditions (except ethanol) to further understand the significance of ethanol in $\mathrm{NaOH}$-ethanol pretreatment. The solid recovery, $p \mathrm{CA}$ release and content of each component in solid residues are shown in Table 4. In general, the solid recovery, $p C A$ release and the glucan and xylan content of $\mathrm{NaOH}$-ethanol-pretreated residues were relatively higher than the corresponding $\mathrm{NaOH}$ pretreated residues, but the lignin content was lower than the $\mathrm{NaOH}$-pretreated residues. These results suggested that ethanol addition promoted the release of $p \mathrm{CA}$ and delignification to a certain extent, but obviously prevented the deconstruction of xylan and cellulose. Compared to $\mathrm{NaOH}$ pretreatment, the release yields of $p \mathrm{CA}$ in pith, rind and whole stem by $\mathrm{NaOH}$-ethanol pretreatment were increased by $8.16 \%, 8.38 \%$ and $8.39 \%$, respectively (Table 4). Meanwhile, the delignification rates were increased by $5.57 \%, 11.47 \%$ and $11.04 \%$, respectively (Fig. 1). The glucan recoveries of pith, rind and whole stem after $\mathrm{NaOH}$-ethanol pretreatment reached $89.78 \%$, $94.85 \%$ and $93.19 \%$, which increased by $10.76 \%, 7.97 \%$

Table 4 The release of $p C A$ during pretreatment, the recovery of the solid residue and the content of each component in solid residues

\begin{tabular}{|c|c|c|c|c|c|c|}
\hline \multirow[t]{2}{*}{ Materials } & \multirow[t]{2}{*}{ Solid recovery (\%) } & \multirow[t]{2}{*}{ Released $p C A(\%)$} & \multicolumn{4}{|l|}{ Composition } \\
\hline & & & Glucan (\%) & Xylan (\%) & Arabinan (\%) & Lignin (\%) \\
\hline \multicolumn{7}{|l|}{$\mathrm{NaOH}$-ethanol } \\
\hline Pith & $59.48 \pm 0.54$ & $94.07 \pm 1.34$ & $56.15 \pm 0.72$ & $23.90 \pm 0.27$ & $2.95 \pm 0.14$ & $5.40 \pm 0.16$ \\
\hline Rind & $75.85 \pm 0.71$ & $97.24 \pm 2.11$ & $50.82 \pm 0.17$ & $20.21 \pm 0.93$ & $2.45 \pm 0.07$ & $10.81 \pm 0.09$ \\
\hline Whole stem & $68.52 \pm 0.59$ & $95.05 \pm 1.57$ & $51.98 \pm 1.04$ & $21.96 \pm 0.12$ & $2.73 \pm 0.20$ & $6.32 \pm 0.21$ \\
\hline \multicolumn{7}{|l|}{$\mathrm{NaOH}$} \\
\hline Pith & $55.74 \pm 1.16$ & $86.97 \pm 0.79$ & $54.10 \pm 0.35$ & $17.26 \pm 1.12$ & $2.64 \pm 0.23$ & $7.49 \pm 1.06$ \\
\hline Rind & $73.42 \pm 0.78$ & $89.72 \pm 1.96$ & $48.63 \pm 1.86$ & $18.14 \pm 0.89$ & $2.12 \pm 0.11$ & $13.39 \pm 0.95$ \\
\hline Whole stem & $64.34 \pm 0.94$ & $87.69 \pm 1.63$ & $51.60 \pm 1.03$ & $17.21 \pm 0.67$ & $2.34 \pm 0.18$ & $9.67 \pm 0.64$ \\
\hline
\end{tabular}

$\mathrm{NaOH}-$ ethanol pretreatment was performed under the following conditions: $1.63 \% \mathrm{NaOH}, 70 \%$ ethanol, $66^{\circ} \mathrm{C}, 3.18 \mathrm{~h} ; 1.90 \% \mathrm{NaOH}, 70 \%$ ethanol, $69.8{ }^{\circ} \mathrm{C}, 1.00 \mathrm{~h}$ and $1.46 \% \mathrm{NaOH}, 70 \%$ ethanol, $70^{\circ} \mathrm{C}, 2.19 \mathrm{~h}$ for the pith, rind and whole stem, respectively. $\mathrm{NaOH}$ pretreatment was performed under the same conditions, except that $70 \%$ ethanol was not included 


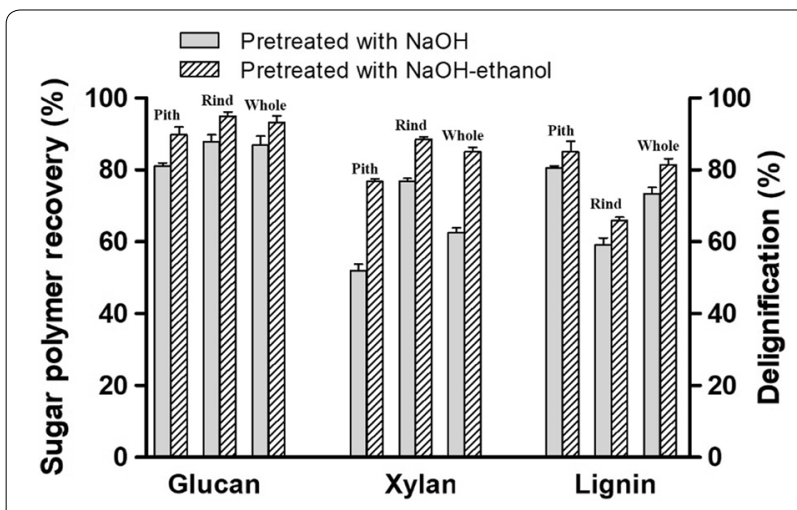

Fig. 1 Sugar recovery (glucan and xylan) and lignin removal after pretreatment. $\mathrm{NaOH}$-ethanol pretreatment was performed under the following conditions: $1.63 \% \mathrm{NaOH}, 70 \%$ ethanol, $66^{\circ} \mathrm{C}, 3.18 \mathrm{~h} ; 1.90 \%$ $\mathrm{NaOH}, 70 \%$ ethanol, $69.8^{\circ} \mathrm{C}, 1.00 \mathrm{~h}$; and $1.46 \% \mathrm{NaOH}, 70 \%$ ethanol, $70^{\circ} \mathrm{C}, 2.19 \mathrm{~h}$ for pith, rind and whole stem, respectively. $\mathrm{NaOH}$ pretreatment was performed under the same conditions, except that $70 \%$ ethanol was not included

and $7.29 \%$ compared to $\mathrm{NaOH}$ pretreatment. The xylan recoveries of pith, rind and whole stem after $\mathrm{NaOH}-$ ethanol pretreatment reached $76.80 \%, 88.46 \%$ and $85.01 \%$, which increased by $47.75 \%, 15.11 \%$ and $35.97 \%$ compared to $\mathrm{NaOH}$ pretreatment (Fig. 1). Despite more delignification by $\mathrm{NaOH}$-ethanol pretreatment, the solid recovery of the $\mathrm{NaOH}-$ ethanol-pretreated pith, rind and whole stem were $6.71 \%, 3.31 \%$ and $6.50 \%$ higher than those of $\mathrm{NaOH}$ pretreatment, respectively, which was mainly due to the improved recovery of glucan and xylan (Table 4). Particularly, the dissolution of xylan in pith was more serious in $\mathrm{NaOH}$ pretreatment condition compared to $\mathrm{NaOH}$-ethanol pretreatment, indicating that addition of ethanol in $\mathrm{NaOH}$ solution could effectively minimize the deconstruction of xylan in pith (Fig. 1). Overall, the addition of ethanol to the $\mathrm{NaOH}$ pretreatment released almost all of esterified $p C A$ while retaining most of cellulose and hemicellulose in the solid residue.

The inhibitors including acetic acid, levulinic acid, furan (furfural and 5-hydroxymethyl furfural (HMF)) and ferulic acid in pretreated liquid fractions were analyzed. The data showed that acetic acid and ferulic acid were the main inhibitors produced during pretreatments (Table 5 ). In comparison, the ferulic acid released in the $\mathrm{NaOH}-$ ethanol-pretreated liquid fraction was slightly more than that in the $\mathrm{NaOH}$-pretreated liquid fraction, but the content of acetic acid was less than that in the $\mathrm{NaOH}$ pretreated liquid fraction. No levulinic acid, furfural and HMF were detected in both pretreated liquid fractions.

\section{Enzymatic hydrolysis of solid residues by Cellic ${ }^{\circledR}$ CTec2}

The enzymatic hydrolysis yields of raw and pretreated materials with Cellulase Cellic ${ }^{\circledR} \mathrm{CTec} 2$ and $\beta$-glucosidase are shown in Fig. 2. The glucose enzymatic hydrolysis yields of $\mathrm{NaOH}$-ethanol-pretreated pith, rind and whole stem were $84.29 \%, 71.22 \%$ and $80.48 \%$, respectively, which were $88.95 \%, 194.54 \%$ and $160.20 \%$ higher than that of untreated pith, rind and whole stem, respectively (Fig. 2a). Similarly, the xylose enzymatic hydrolysis yields of $\mathrm{NaOH}$-ethanol-pretreated pith, rind and whole stem were $78.33 \%, 62.70 \%$ and $75.53 \%$, respectively, which were $59.89 \%, 87.78 \%$ and $117.23 \%$ higher than untreated pith, rind and whole stem, respectively (Fig. 2b). The enzymatic hydrolysis efficiency of the $\mathrm{NaOH}-$ ethanolpretreated residues was also obviously higher than that of $\mathrm{NaOH}$-pretreated residues. The glucose enzymatic hydrolysis yields of $\mathrm{NaOH}$-ethanol-pretreated pith, rind and whole stem were $7.39 \%, 15.45 \%$ and $12.18 \%$ higher than that of the $\mathrm{NaOH}$-pretreated pith, rind and whole stem, respectively (Fig. 2a). The xylose enzymatic hydrolysis yields of $\mathrm{NaOH}$-ethanol-pretreated pith, rind and

Table 5 Inhibitors produced in liquid fractions during the pretreatment of sorghum pith, rind and whole stem

\begin{tabular}{|c|c|c|c|c|c|}
\hline Materials & Ferulic acid (g/L) & Acetic acid (g/L) & Levulinic acid (g/L) & Furfural (g/L) & HMF (g/L) \\
\hline \multicolumn{6}{|l|}{$\mathrm{NaOH}$-ethanol } \\
\hline Pith & 0.184 & 1.428 & n.d. & n.d. & n.d. \\
\hline Rind & 0.210 & 1.448 & & & \\
\hline Whole stem & 0.204 & 1.490 & & & \\
\hline \multicolumn{6}{|l|}{$\mathrm{NaOH}$} \\
\hline Pith & 0.183 & 1.462 & n.d. & n.d. & n.d. \\
\hline Rind & 0.194 & 1.487 & & & \\
\hline Whole stem & 0.186 & 1.521 & & & \\
\hline
\end{tabular}

$\mathrm{NaOH}$-ethanol pretreatment was performed under the following conditions: $1.63 \% \mathrm{NaOH}, 70 \%$ ethanol, $66^{\circ} \mathrm{C}, 3.18 \mathrm{~h} ; 1.90 \% \mathrm{NaOH}, 70 \%$ ethanol, $69.8{ }^{\circ} \mathrm{C}, 1.00 \mathrm{~h}$ and $1.46 \% \mathrm{NaOH}, 70 \%$ ethanol, $70^{\circ} \mathrm{C}, 2.19 \mathrm{~h}$ for the pith, rind and whole stem, respectively. $\mathrm{NaOH}$ pretreatment was performed under the same conditions, except that $70 \%$ ethanol was not included

n.d. not detected 

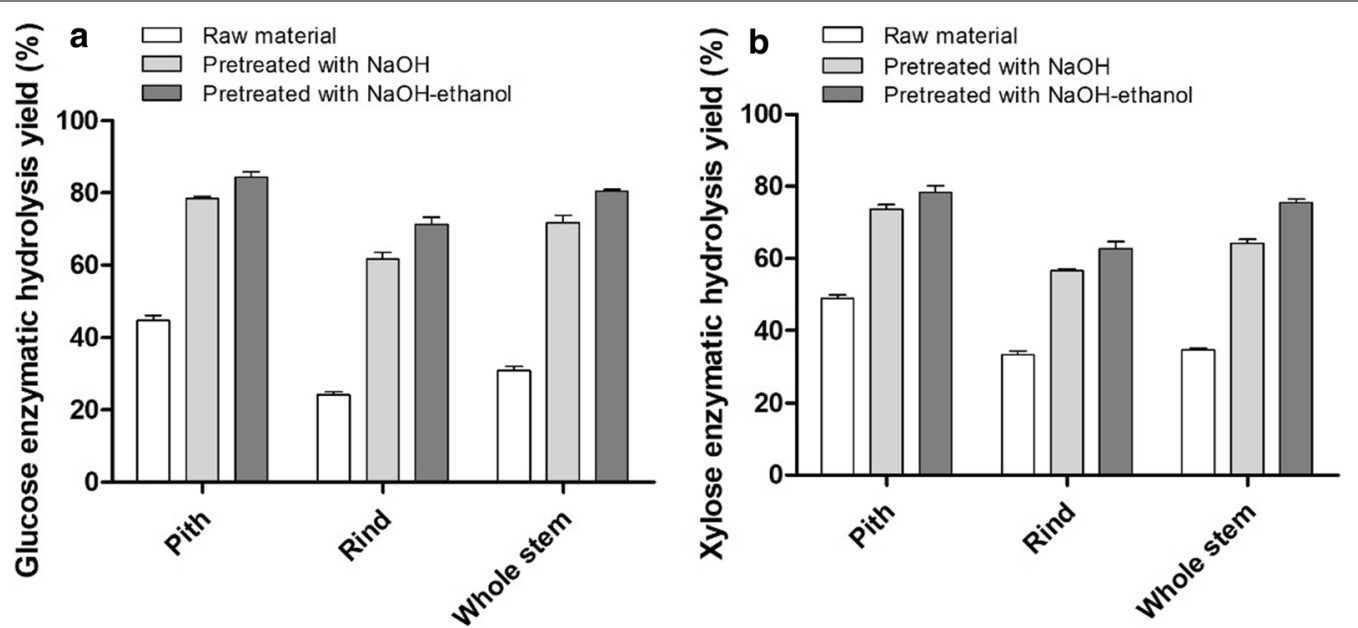

Fig. 2 Glucose (a) and xylose (b) enzymatic hydrolysis yields of raw and pretreated materials. The sample (2\%, w/v) was hydrolyzed at $50^{\circ} \mathrm{C}$ for $72 \mathrm{~h}$ using Cellic ${ }^{\circledR}$ CTec2 (15 FPU/g substrate) and $\beta$-glucosidase (30 CBU/g substrate)

whole stem were $6.43 \%, 10.86 \%$ and $17.61 \%$ higher than $\mathrm{NaOH}$-pretreated pith, rind and whole stem, respectively (Fig. 2b). This may be attributed to more effective in delignification by $\mathrm{NaOH}-$ ethanol pretreatment compared to that of $\mathrm{NaOH}$ pretreatment, because lignin is one of the major factors inhibiting enzymatic saccharification [32]. This result was consistent with the previous finding reported by Huang et al. [28]. They described that the introduction of ethanol into alkaline peroxide pretreatment enhanced the delignification of bamboo and thus improved its enzymatic hydrolysis efficiency. In addition, the improvement of the enzymatic saccharification efficiency of the $\mathrm{NaOH}$-ethanol-pretreated residues might be also partly brought by its higher release of $p \mathrm{CA}$ compared to $\mathrm{NaOH}$ pretreatment, since it has been reported that the presence of phenolic acids in residues has a negative effect on the enzymatic hydrolysis of lignocellulose [33]. In summary, alkali organosolv pretreatment not only reduces the over-degradation of cellulose and hemicellulose, but also enhances the delignification of biomass, resulting in enhanced enzymatic digestion of biomass $[34,35]$.

\section{Effect of xylanase on enzymatic hydrolysis of solid residues by Cellic ${ }^{\circledR}$ CTec2}

Since relatively high xylan was retained in $\mathrm{NaOH}$-ethanolpretreated residues, the saccharification of cellulose may be still impeded by the highly reserved xylan in the lignocellulosic matrix [36]. Therefore, the effect of xylanase (Sigma X2629-100g) on enzymatic hydrolysis of solid residues was studied by adding xylanase to enzymatic hydrolysis system. Three different dosages of xylanase (5 BXU, 10 BXU and $15 \mathrm{BXU} / \mathrm{g}$ substrate) were selected for the enzymatic hydrolysis of $\mathrm{NaOH}$-ethanol-pretreated solid residues, and the results are shown in Fig. 3. After the addition of xylanase, the enzymatic hydrolysis yields of glucose and xylose were gradually improved with the increase of xylanase dosage (Fig. 3). This was attributable to the increased accessibility of cellulose to cellulase when xylan was degraded by xylanase. As shown in Fig. 4, when the dosage of xylanase was $15 \mathrm{BXU} / \mathrm{g}$ substrate, the glucose enzymatic hydrolysis yields of $\mathrm{NaOH}$-ethanol-pretreated pith, rind and whole stem reached $97.93 \%, 88.71 \%$ and $91.98 \%$, respectively, which increased by $16.18 \%, 24.56 \%$ and $14.29 \%$ compared to those without xylanase (Fig. 4a), and the xylose enzymatic hydrolysis yields also reached $99.34 \%, 88.11 \%$ and $94.79 \%$ (Fig. 4b), which increased by $26.82 \%, 40.53 \%$ and $25.50 \%$ compared to those without xylanase. Similarly, the glucose enzymatic hydrolysis and xylose enzymatic hydrolysis yields were also increased when xylanase was added during the enzymatic hydrolysis of $\mathrm{NaOH}$-pretreated sample. The glucose enzymatic hydrolysis yields of the $\mathrm{NaOH}$-pretreated pith, rind and whole stem reached $90.36 \%, 78.86 \%$ and $84.00 \%$, respectively, which increased by $15.12 \%, 27.83 \%$ and $17.09 \%$ compared to those without xylanase, and the xylose enzymatic hydrolysis yields were enhanced to $92.43 \%, 78.22 \%$ and $86.41 \%$, respectively, which increased by $25.58 \%, 38.30 \%$ and $34.55 \%$ compared to those without xylanase (Fig. 4a, b). These results confirmed the promoting effect of xylanase on enzymatic hydrolysis of solid residues, which was consistent with the previous report of negative effects of retaining xylan on enzymatic hydrolysis of cellulose [37]. In comparison, the percentage increases in enzymatic saccharification by adding xylanase are more significant in rind than pith, probably due to higher recovered xylan in rind. 

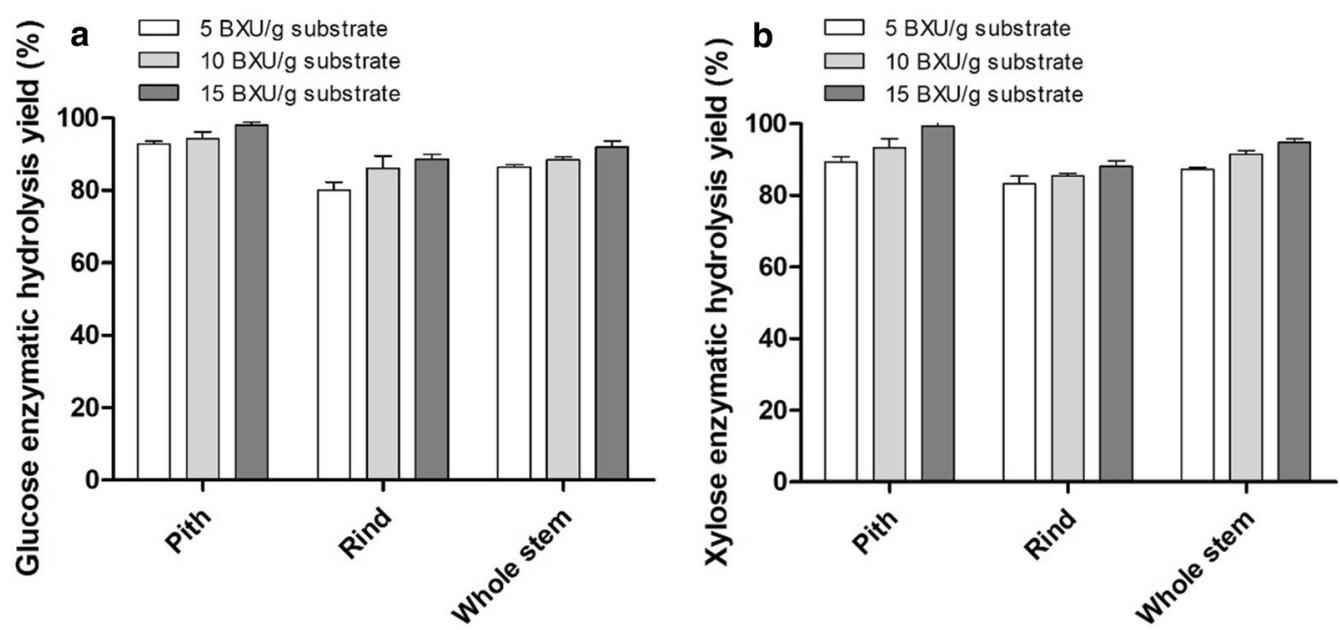

Fig. 3 Effect of different dosages of adding xylanase on enzymatic hydrolysis of $\mathrm{NaOH}$-ethanol-pretreated materials. The sample (2\%, w/v) was hydrolyzed at $50{ }^{\circ} \mathrm{C}$ for $72 \mathrm{~h}$ using cellulose cocktail (15 FPU/g substrate Cellic ${ }^{\circledR} \mathrm{CTec}$, $30 \mathrm{CBU} / \mathrm{g}$ substrate $\beta$-glucosidase and 5-15 BXU/g substrate xylanase)

The total ${ }_{\text {Glu }}$ yields and total $\mathrm{Xyl}_{\mathrm{y}}$. yields of various pretreated materials after adding xylanase $(15 \mathrm{BXU} / \mathrm{g}$ substrate) were calculated. In above condition, the total Glu. $_{1}$. yields of $\mathrm{NaOH}$-ethanol-pretreated pith, rind and whole stem were $87.92 \%, 84.14 \%$ and $85.72 \%$, respectively (Fig. 4c), which were $20.03 \%, 21.45 \%$ and $17.49 \%$, respectively, higher than those of $\mathrm{NaOH}$-pretreated samples. The total $_{\text {Xyl }}$. yields were $76.29 \%, 77.94 \%$ and $80.58 \%$ (Fig. 4d), which were $58.77 \%, 29.66 \%$ and $49.17 \%$, respectively, higher than those of $\mathrm{NaOH}$-pretreated samples. Taken together, the total reducing sugar yields (glucose and xylose) after enzymatic hydrolysis reached $84.06 \%, 82.29 \%$ and $84.09 \%$ for $\mathrm{NaOH}$-ethanol-pretreated pith, rind and whole stem, respectively, which were $29.56 \%, 23.67 \%$ and $25.56 \%$ higher than the corresponding $\mathrm{NaOH}$-pretreated samples. The substantial increase of total reducing sugar yields was attributed to the improvement in both solid recovery and enzymatic hydrolysis yields when using $\mathrm{NaOH}-$ ethanol pretreatment. It was worth noting that the total $_{\mathrm{Xyl}}$. yield of the $\mathrm{NaOH}$-pretreated pith was lower than that of the untreated pith, because nearly half of the xylan was degraded during the $\mathrm{NaOH}$ pretreatment.

\section{Structural characterization of untreated and pretreated sorghum sample FTIR spectrum analysis}

The aromatic structure strength and functional group identification of the untreated and treated samples were investigated using FTIR techniques. FTIR spectra of the untreated and treated samples are shown in Additional file 1: Fig. S2. The wavelength assignments of the lignin-, cellulose- and hemicellulose-related bands are summarized in Additional file 1: Table S2. Absorption spectra at $1732 / \mathrm{cm}$ are due to the ester-linked acetyl, feruloyl and $p$-coumaroyl groups on hemicellulose and/or lignin [38]. The band of the pretreated material at 1732/ $\mathrm{cm}$ almost completely disappeared, indicating that almost all of the ester-linked phenolic acid were released into the liquid. The bands at $1106 / \mathrm{cm}, 1254 / \mathrm{cm}$ and $1513 / \mathrm{cm}$ are characteristic bands of lignin [39]. These lignin-related bands were significantly reduced after treatment, indicating that most of the lignin was removed during pretreatment. After pretreatment, the characteristic band of the $\beta$-anomer or the $\beta$-linked glucose polymer increased significantly at $899 / \mathrm{cm}$, indicating a significant increase in the cellulose content in the treated residue [40]. In summary, FTIR spectroscopy results show that the pretreatment can break the ester bond of $p C A$ to lignin and remove most of the lignin.

\section{SEM analysis}

To observe the changes in the substrate surface, SEM was applied to investigate the morphological features and surface characteristics of the raw and the pretreated pith, rind and whole stem. As can be seen from Additional file 1: Fig. S3, the surface of the raw material was relatively smooth. The surfaces of the pretreated residue were altered with evident coarse surface and porous areas. Available surface area of the cellulose fiber structure is essential for enzymatic hydrolysis of lignocellulosic materials [41]. Both $\mathrm{NaOH}$-ethanol and $\mathrm{NaOH}$ pretreatment destroyed the recalcitrant structure of the lignocelluloses, increased the surface area and porosity of biomass, which accelerated the saccharification process. 

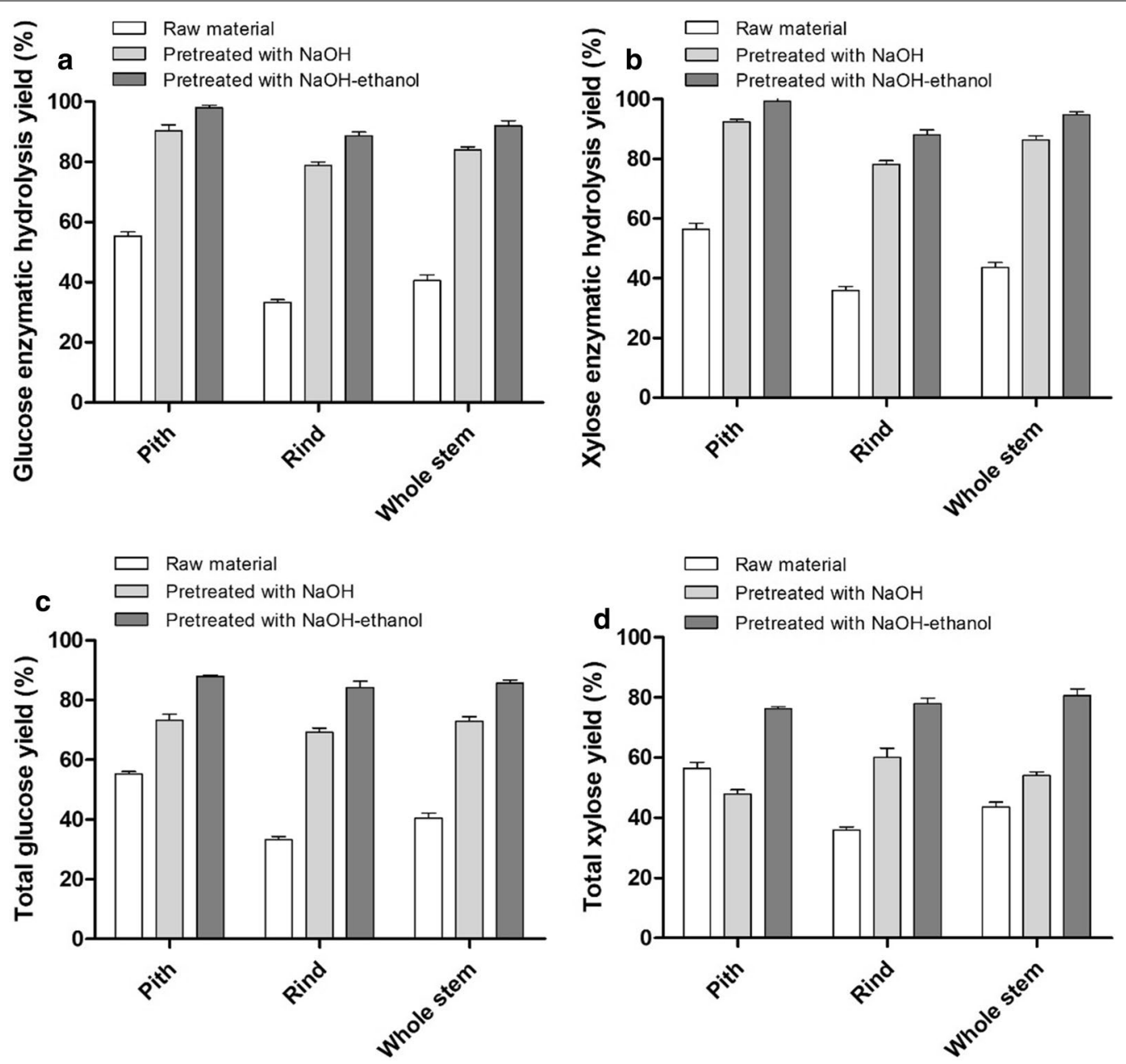

Fig. 4 Comparison of enzymatic hydrolysis yields [glucose (a) and xylose (b)] and total yields of sugar [glucose (c) and xylose (d)] of raw, $\mathrm{NaOH}$-pretreated and $\mathrm{NaOH}$-ethanol-pretreated materials with adding xylanase. The sample $(2 \%, \mathrm{w} / \mathrm{v})$ was hydrolyzed at $50^{\circ} \mathrm{C}$ for $72 \mathrm{~h}$ using cellulose cocktail (15 FPU/g substrate Cellic ${ }^{\circledR}$ CTec2, 30 CBU/g substrate $\beta$-glucosidase and 15 BXU/g substrate xylanase)

\section{XRD analysis}

The crystallinity index (CrI) was calculated according to X-ray diffractograms. XRD analysis of untreated and pretreated sorghum samples is shown in Additional file 1: Fig. S4. In raw materials, the CrI of the pith, rind and whole stem were $30.29 \%, 34.61 \%$ and $30.84 \%$, respectively. After $\mathrm{NaOH}$-ethanol pretreatment, the $\mathrm{CrI}$ of pith, rind and whole stem were increased to $63.01 \%, 43.27 \%$ and $54.41 \%$, respectively. Similarly, the $\mathrm{CrI}$ of $\mathrm{NaOH}$-pretreated pith, rind and whole stem were also increased to $58.14 \%, 42.17 \%$ and $45.86 \%$, respectively. Lignocellulosic crystallinity was considered as an important characteristic for enzymatic digestibility [42]. According to previous reports, the CrI of lignocelluloses was inversely related to the amorphous substances in cell wall where degradation of hemicelluloses and disordered fractions of cellulose, and delignification can all make the $\mathrm{CrI}$ increase [36]. Therefore, higher $\mathrm{CrI}$ of $\mathrm{NaOH}$-ethanol-pretreated residue may be due to the higher level of lignin removal and the recovery of cellulose compared to $\mathrm{NaOH}$-pretreated residue.

\section{Overall mass balance}

The process of pretreatment and enzymatic saccharification of sorghum samples $(20 \mathrm{~g})$ is shown in Fig. $5 . \mathrm{NaOH}-$ ethanol pretreatment of the pith, rind and whole stem was performed under the respective optimal conditions. Enzymatic saccharification of pretreated pith, rind and whole stem yielded $6.98 \mathrm{~g}, 7.54 \mathrm{~g}$ and $7.13 \mathrm{~g}$ of glucose, respectively, which accounted for $84.37 \%, 83.46 \%$ and $84.02 \%$ of the glucose in sorghum pith, rind and whole stem, respectively. Meanwhile, enzymatic saccharification produced $3.23 \mathrm{~g}, 3.04 \mathrm{~g}$ and $3.18 \mathrm{~g}$ of xylose, respectively, which accounted for $76.72 \%, 77.21 \%$ and $79.16 \%$ of the xylose in sorghum pith, rind and whole stem, respectively. After acidification, the $\mathrm{NaOH}$-ethanol-pretreated 


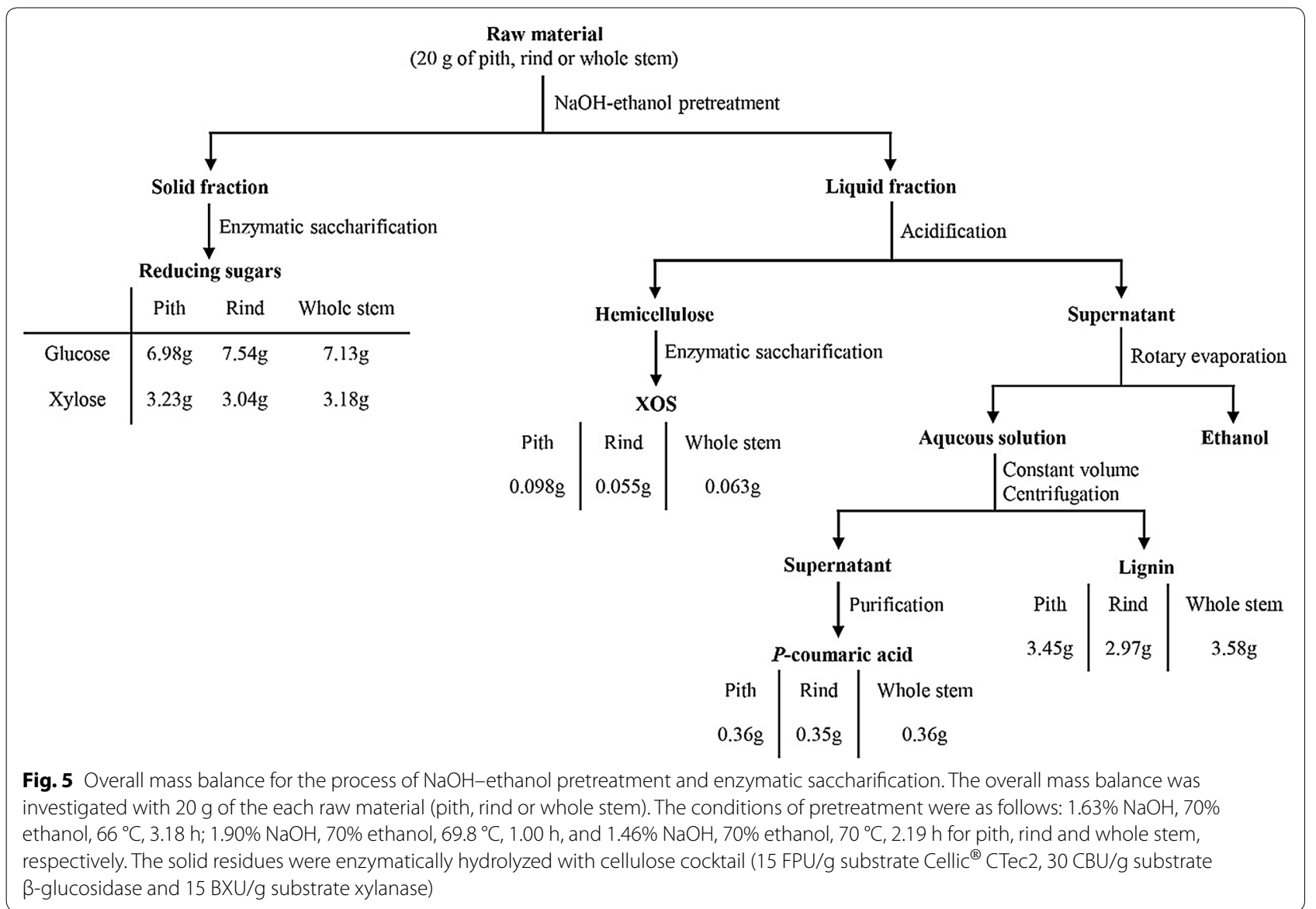

liquid fractions of pith, rind and whole stem contained $0.41 \mathrm{~g}, 0.40 \mathrm{~g}$ and $0.40 \mathrm{~g}$ of $p \mathrm{CA}$, respectively. Macroporous adsorption resin D101 was used to recover $p C A$, and the adsorption rate and desorption rate reached $96 \%$ and $91 \%$, respectively. After desorption from resin column, the recovered $p$ CA were $0.36 \mathrm{~g}, 0.35 \mathrm{~g}$ and $0.36 \mathrm{~g}$, which accounted for $81.45 \%, 84.13 \%$ and $84.51 \%$ of the esterified $p C A$ in sorghum pith, rind and whole stem, respectively. Since the macroporous adsorption resin also has an adsorption capacity on other hydroxycinnamic acid derivatives such as ferulic acid in liquid fraction, further purification procedure will be needed to obtain high purity of $p C A$. In this study, optimization using the response surface methodology revealed that the pith, rind and whole stem require different $\mathrm{NaOH}$-ethanol pretreatment conditions for maximal $p C A$ release and xylan preservation due to the difference in cell type and chemical composition of the pith and rind. From the perspective of $p C A$ release yield and total sugar yield, however, there were no huge differences between the pith and rind if they were pretreated by respective optimal $\mathrm{NaOH}-$ ethanol conditions. Considering the separation cost of the different stem parts, whole sorghum stem can be directly used as feedstock for biorefinery.

Moreover, the hemicellulose obtained from the liquid fractions of the pretreated pith, rind, and whole stem was $0.74 \mathrm{~g}, 0.38 \mathrm{~g}$ and $0.51 \mathrm{~g}$, respectively, which contained $42.64 \%, 44.29 \%$ and $40.97 \%$ of xylan, respectively. The hemicellulose was collected and subjected to enzymatic hydrolysis for production of xylooligosaccharides (XOS). EpXYN1 displayed the best enzymatic hydrolysis efficiency, and the total XOS (xylobiose to xylohexaose) yields based on xylan from the pretreated pith, rind and whole stem were $31.19 \%, 32.71 \%$ and $30.28 \%$, respectively (Additional file 1: Table S3). The results suggested that the dissolved xylan during the $\mathrm{NaOH}$-ethanol pretreatment process can also be utilized for XOS production.

\section{Conclusions}

In this study, $\mathrm{NaOH}$-ethanol pretreatment was used to treat different parts of the sorghum (pith and rind) to enhance the release of $p C A$ and the recovery of total reducing sugars. The pith, rind and whole stem required different pretreatment conditions due to structure chemical composition differences. Under optimized conditions, 
the rind acquired higher $p C A$ release and xylan recovery than the pith. There was no significant difference in the total sugar yield of different stem parts by respective optimal $\mathrm{NaOH}$-ethanol pretreatment, so whole sorghum stem can be directly used as feedstock for biological refining in industrial production. Compared to $\mathrm{NaOH}$ pretreatment, higher release of $p \mathrm{CA}$ and recovery of hemicellulose were obtained in $\mathrm{NaOH}$-ethanol pretreatment. The total reducing sugar yield was enhanced after $\mathrm{NaOH}-$ ethanol pretreatment and enzymatic hydrolysis because of the improvement of enzymatic hydrolysis and sugar polymers (glucan and xylan) recovery. All the results suggested that $\mathrm{NaOH}$-ethanol pretreatment is a promise pretreatment method of sorghum biorefinery for product fermentable sugars and value-added products.

\section{Materials and methods}

\section{Materials}

Sorghum stem was obtained from Hengshui, Hebei Province, China. The pith and rind were separated by manual peeling with a sharp knife and washed three times with tap water to remove field dirt. After drying at $65{ }^{\circ} \mathrm{C}$, sorghum samples were ground and passed through 40-mesh sieve. Cellulase Cellic ${ }^{\circledR}$ CTec2 (89 FPU/g) and

\section{$\mathrm{NaOH}$-ethanol pretreatment of different sorghum stem} parts

The $\mathrm{NaOH}$-ethanol pretreatment experiments were carried out with different temperature $\left(60-70{ }^{\circ} \mathrm{C}\right)$ and time $(1-4 \mathrm{~h})$ in a plastic centrifuge tube. One gram of sorghum stem was suspended in $20 \mathrm{~mL}$ of mixed solution of $\mathrm{NaOH}(0.5-2 \%, \mathrm{w} / \mathrm{v})$ and ethanol $(10-70 \%, \mathrm{w} / \mathrm{v})$. Addition of $\mathrm{NaHSO}_{3}(100 \mathrm{mg} / \mathrm{L})$ prevents oxidation of the phenolic acid. The whole slurry was separated by vacuum filtration and washed by equal volume of water, then the liquids were combined. The treated solid was washed with water until the filtrate reached a neutral $\mathrm{pH}$ and then dried at $65^{\circ} \mathrm{C}$ for the following experiments. The $\mathrm{pH}$ of $\mathrm{NaOH}$-ethanol-extracted liquid fraction was adjusted to 1-2 with $\mathrm{HCl}$, and then 1.5 times the volume of absolute ethanol was added to precipitate hemicellulose and allowed to stand at $4{ }^{\circ} \mathrm{C}$ for $24 \mathrm{~h}$. The precipitate was collected as extracted xylan by centrifugation and dried at $65{ }^{\circ} \mathrm{C}$ for the following experiments. The liquid fraction was rotary evaporated to recover ethanol, and then the $p C A$ was analyzed by high-performance liquid chromatography (HPLC, Agilent 1260, USA).

The solid recovery, $p C A$ release, xylan recovery, glucan recovery, and delignification were calculated according to the following equations, respectively:

Solid recovery yield $(\%)=100 \times$ Regenerated residue/Raw material

$p$ CA release yield $(\%)=100 \times$ Amount of release $p$ CA after pretreatment/Amount of $p$ CA in raw material

Xylan recovery yield $(\%)=100 \times(0.88 \times$ Amount of xylose in the residue $) /$ Amount of xylan in raw material

Glucan recovery yield $(\%)=100 \times(0.9 \times$ Amount of glucose in residue $) /$ Amount of glucan in raw material

Delignification yield $(\%)=100 \times($ Amount of lignin in raw material - amount of lignin in residue $) /$ Amount of lignin in raw material

$\beta$-glucosidase (Novozyme 188, $300 \mathrm{CBU} / \mathrm{mL}$ ) were purchased from Novozymes China (Shanghai, China). Commercial xylanase (X2629-100g, $470 \mathrm{BXU} / \mathrm{g}$ ) was purchased from Sigma-Aldrich (Shanghai, China). The xylanase EpXYN1 (130 BXU/mL), EpXYN3 (722 BXU/ $\mathrm{mL})$ and XynII (546 BXU/mL) were prepared according to our previous researches $[43,44]$. Other chemicals and reagents used in this study were of analytical grade.

\section{Enzymatic hydrolysis \\ Enzymatic hydrolysis of solid residue by Cellic ${ }^{\circledR}$ CTec2 with or without xylanase}

The pretreated residue was enzymatically hydrolyzed in a conical flask with phosphate buffer $(\mathrm{pH} 4.8)$, and the substrate was added at $2 \%(\mathrm{w} / \mathrm{v})$. Sodium azide $(10 \mathrm{mM})$ was also added to the solution to prevent microbial contamination. The enzymatic hydrolysis was conducted at $50{ }^{\circ} \mathrm{C}$ for $72 \mathrm{~h}$ in the presence of Cellic ${ }^{\circledR} \mathrm{CTec} 2$ cellulase (15 FPU/g substrate), $\beta$-glucosidase (30 CBU/g substrate) 
with/without xylanase (Sigma X2629-100 g) in a shaking incubator at $150 \mathrm{rpm}$.

The glucose enzymatic hydrolysis yield, xylose enzymatic hydrolysis yield, total glucose yield, and total xylose yield were calculated according to the equations as follows:

Glucose enzymatic hydrolysis yield (\%) $=100 \times(0.9 \times$ Amount of released glucose after enzymatic hydrolysis $) /$ Amount of glucan in residue

Xylose enzymatic hydrolysis yield (\%) $=100 \times(0.88 \times$ Amount of released xylose after enzymatic hydrolysis $) /$ Amount of xylan in residue

Total glucose yield (Total $\left.{ }_{\text {Glu. }}, \%\right)$ $=100 \times(0.9 \times$ Amount of glucose in residue $\times$ glucose hydrolysis yield $) /$ Amount of glucan in raw material

Total xylose yield $\left(\right.$ Total $\left._{\text {Xyl. }}, \%\right)$ $=100 \times(0.88 \times$ Amount of xylose in residue $\times$ xylan hydrolysis yield $) /$ Amount of xylan in raw material according to the National Renewable Energy Laboratory standard procedure but the ethanol extractives in samples were not removed prior to the determination [45]. Glucose, xylose, arabinose, acetic acid, levulinic acid, furfural and HMF were determined using HPLC (Agilent 1100, USA) consisting of refractive index detector and a column of Bio-Rad Aminex HPX-87H column

\section{Enzymatic hydrolysis of extracted xylan}

The enzymatic hydrolysis of extracted xylan from the liquid fraction of $\mathrm{NaOH}$-ethanol-pretreated samples was carried out in phosphate buffer with a final solid loading of $5 \%(\mathrm{w} / \mathrm{v})$ and $20 \mathrm{BXU} / \mathrm{g}$ substrate of xylanase. Sodium azide $(10 \mathrm{mM})$ was added to the solution to prevent microbial contamination. The enzymatic hydrolysis process was incubated at optimum $\mathrm{pH}$ and optimum temperature for each enzyme (EpXYN1 and EpXYN3 at pH $4.8,50{ }^{\circ} \mathrm{C}$; XynII at $\mathrm{pH} 7.0,60{ }^{\circ} \mathrm{C}$ ) at $150 \mathrm{rpm}$ in a shaking incubator for $24 \mathrm{~h}$. The XOS in the supernatant was analyzed using ion chromatography (Dionex ICS-3000, USA).

\section{Experimental design and statistical analysis}

The various process parameters involved in $\mathrm{NaOH}$-ethanol pretreatment of different sorghum stem parts were evaluated using Box-Behnken design of Design Expert 11. The variables selected were $\mathrm{NaOH}$ loading $(0.5-2 \%$, $\mathrm{w} / \mathrm{v})$, ethanol content $(10-70 \%, \mathrm{v} / \mathrm{v})$, temperature $(60-$ $70{ }^{\circ} \mathrm{C}$ ) and time $(1-4 \mathrm{~h})$. The analytical responses were $p C A$ release yield (\%) and xylan recovery yield (\%). A total of 29 runs were designed and 5 replicates were performed at the center point.

\section{Analytical methods}

The contents of esterified phenolic acid ( $p C A$ and ferulic acid) in the sorghum pith, rind and whole stem were analyzed according to the method described by Jiang et al. [8]. The structural components of glucan, xylan, arabinan and lignin of raw and pretreated samples were determined using the two-step acid hydrolysis method 
hydrolysis. The $\mathrm{pH}$ of liquid fraction was adjusted to 1-2 with $\mathrm{HCl}$, and 1.5 times the volume of absolute ethanol was added to the supernatant and stored at $4{ }^{\circ} \mathrm{C}$ for $24 \mathrm{~h}$. Xylan precipitate was separated by centrifugation and dried for enzymatic hydrolysis, then ethanol was recovered using a rotary evaporator. Distilled water was added to the remaining liquid to replenish the original volume, and centrifuge to remove lignin. Macroporous adsorption resins D101 was used to adsorb $p$ CA in the supernatant and desorbed with $70 \%(\mathrm{v} / \mathrm{v})$ ethanol. PCA in the eluent was detected by HPLC.

\section{Supplementary information}

Supplementary information accompanies this paper at https://doi. org/10.1186/s13068-020-01746-4.

Additional file 1. Additional figures and tables.

\section{Abbreviations}

PCA: $p$-Coumaric acid; FTIR: Fourier transform infrared; SEM: Scanning electron microscopy; XRD: X-ray diffraction; HMF: 5-Hydroxymethyl furfural; HPLC: Highperformance liquid chromatography; FPU: Filter paper units; CBU: Cellobiase units; BXU: Birch xylan units; XOS: Xylooligosaccharides; Crl: Refractive index.

\section{Acknowledgements}

We thank the 948 research project (No. 2013-4-16) from State Forestry Administration of China, a project funded by the Priority Academic Program Development of Jiangsu Higher Education Institutions, and the Doctorate Fellowship Foundation of Nanjing Forestry University.

\section{Authors' contributions}

$D L$ researched and drafted the manuscript. LL provided some experimental materials and guided the experimental process. SD interpreted the experimental data and reviewed the manuscript. All authors read and approved the final manuscript.

\section{Funding}

This work was supported by a 948 research project (No. 2013-4-16) from State Forestry Administration of China, a project funded by the Priority Academic Program Development of Jiangsu Higher Education Institutions, and the Doctorate Fellowship Foundation of Nanjing Forestry University.

\section{Availability of data and materials}

All data generated or analyzed during this study are included in this manuscript and its additional file.

\section{Ethics approval and consent to participate}

Not applicable.

\section{Consent for publication}

Not applicable.

\section{Competing interests}

The authors declare that they have no competing interests.

Received: 13 March 2020 Accepted: 2 June 2020

Published online: 10 June 2020

\section{References}

1. Chaturvedi V, Verma P. An overview of key pretreatment processes employed for bioconversion of lignocellulosic biomass into biofuels and value added products. 3 Biotech. 2013;3:415-31.
2. Behera S, Arora R, Nandhagopal N, Kumar S. Importance of chemical pretreatment for bioconversion of lignocellulosic biomass. Renew Sustain Energy Rev. 2014;36:91-106.

3. Kumar AK, Sharma S. Recent updates on different methods of pretreatment of lignocellulosic feedstocks: a review. Bioresour Bioprocess. 2017:4:7.

4. Bhatia SK, Jagtap SS, Bedekar AA, Bhatia RK, Patel AK, Pant D, Rajesh Banu J, Rao CV, Kim YG, Yang YH. Recent developments in pretreatment technologies on lignocellulosic biomass: effect of key parameters, technological improvements, and challenges. Bioresour Technol. 2020;300:122724.

5. Goshadrou A. Bioethanol production from Cogongrass by sequential recycling of black liquor and wastewater in a mild-alkali pretreatment. Fuel. 2019;258.

6. Kim JS, Lee YY, Kim TH. A review on alkaline pretreatment technology for bioconversion of lignocellulosic biomass. Bioresour Technol. 2016;199:42-8

7. Wang W, Wang XM, Zhang Y, Yu Q, Tan XS, Zhuang XS, Yuan ZH. Effect of sodium hydroxide pretreatment on physicochemical changes and enzymatic hydrolysis of herbaceous and woody lignocelluloses. Ind Crop Prod. 2020;145:8

8. Jiang K, Li L, Long L, Ding S. Comparison of alkali treatments for efficient release of $p$-coumaric acid and enzymatic saccharification of sorghum pith. Bioresour Technol. 2016;207:1-10.

9. Tsegaye B, Balomajumder C, Roy P. Alkali pretreatment of wheat straw followed by microbial hydrolysis for bioethanol production. Environ Technol. 2019;40:1203-11.

10. Tang S, Dong Q, Fang Z, Miao Z-D. Complete recovery of cellulose from rice straw pretreated with ethylene glycol and aluminum chloride for enzymatic hydrolysis. Bioresour Technol. 2019;284:98-104.

11. Girio FM, Fonseca C, Carvalheiro F, Duarte LC, Marques S, BogelLukasik R. Hemicelluloses for fuel ethanol: a review. Bioresour Technol. 2010;101:4775-800

12. Avanthi A, Kumar S, Sherpa KC, Banerjee R. Bioconversion of hemicelIuloses of lignocellulosic biomass to ethanol: an attempt to utilize pentose sugars. Biofuels. 2017:8:431-44.

13. Saha BC. Hemicellulose bioconversion. J Ind Microbiol Biotechnol. 2003;30:279-91.

14. Bonechi C, Consumi M, Donati A, Leone G, Magnani A, Tamasi G, Rossi C. 1-biomass: an overview. In: Dalena F, Basile A, editors. Bioenergy systems for the future. Rossi C: Woodhead Publishing; 2017. p. 3-42.

15. Liu KX, Li HQ, Zhang J, Zhang ZG, Xu J. The effect of non-structural components and lignin on hemicellulose extraction. Bioresour Technol. 2016;214:755-60

16. Yuan W, Gong Z, Wang G, Zhou W, Liu Y, Wang X, Zhao M. Alkaline organosolv pretreatment of corn stover for enhancing the enzymatic digestibility. Bioresour Technol. 2018;265:464-70.

17. Wei L, Yan T, Wu Y, Chen H, Zhang B. Optimization of alkaline extraction of hemicellulose from sweet sorghum bagasse and its direct application for the production of acidic xylooligosaccharides by Bacillus subtilis strain MR44. PLOS ONE. 2018;13:e0195616.

18. Zegada-Lizarazu W, Monti A. Are we ready to cultivate sweet sorghum as a bioenergy feedstock? A review on field management practices. Biomass Bioenerg. 2012;40:1-12.

19. Appiah-Nkansah NB, Li J, Rooney W, Wang DH. A review of sweet sorghum as a viable renewable bioenergy crop and its techno-economic analysis. Renew Energy. 2019;143:1121-32.

20. Li M, Feng S, Wu L, Li Y, Fan C, Zhang R, Zou W, Tu Y, Jing H-C, Li S, Peng L. Sugar-rich sweet sorghum is distinctively affected by wall polymer features for biomass digestibility and ethanol fermentation in bagasse. Bioresour Technol. 2014;167:14-23.

21. Hatfield RD, Wilson JR, Mertens DR. Composition of cell walls isolated from cell types of grain sorghum stems. J Sci Food Agric. 1999;79:891-9.

22. Tran Ngoc L, Fujita H, Sakoda A. Release kinetics of esterified p-coumaric acid and ferulic acid from rice straw in mild alkaline solution. Bioresour Technol. 2017;232:192-203.

23. Ferreira PS, Victorelli FD, Fonseca-Santos B, Chorilli M. A review of analytical methods for $p$-coumaric acid in plant-based products, beverages, and biological matrices. Crit Rev Anal Chem. 2019;49:21-31.

24. Boz H. p-Coumaric acid in cereals: presence, antioxidant and antimicrobial effects. Int J Food Sci Technol. 2015;50:2323-8. 
25. Hu H, Li L, Ding S. An organic solvent-tolerant phenolic acid decarboxylase from Bacillus licheniformis for the efficient bioconversion of hydroxycinnamic acids to vinyl phenol derivatives. Appl Microbio Biotechnol. 2015;99:5071-81.

26. Sun RC, Sun XF, Wang SQ, Zhu W, Wang XY. Ester and ether linkages between hydroxycinnamic acids and lignins from wheat, rice, rye, and barley straws, maize stems, and fast-growing poplar wood. Ind Crop Prod. 2002;15:179-88.

27. Costa THF, Masarin F, Bonifacio TO, Milagres AMF, Ferraz A. The enzymatic recalcitrance of internodes of sugar cane hybrids with contrasting lignin contents. Ind Crop Prod. 2013;51:202-11.

28. Huang C, Fang G, Yu L, Zhou Y, Meng X, Deng Y, Shen K, Ragauskas AJ. Maximizing enzymatic hydrolysis efficiency of bamboo with a mild ethanol-assistant alkaline peroxide pretreatment. Bioresour Technol. 2019;299:122568.

29. Damay J, Duret X, Ghislain T, Lalonde O, Lavoie JM. Steam explosion of sweet sorghum stems: optimisation of the production of sugars by response surface methodology combined with the severity factor. Ind Crop Prod. 2018;111:482-93.

30. Varnai A, Costa THF, Faulds CB, Milagres AMF, Siika-aho M, Ferraz A. Effects of enzymatic removal of plant cell wall acylation (acetylation, p-coumaroylation, and feruloylation) on accessibility of cellulose and xylan in natural (non-pretreated) sugar cane fractions. Biotechnol Biofuels. 2014;7:153.

31. del Rio JC, Rencoret J, Prinsen P, Martinez AT, Ralph J, Gutierrez A. Structural characterization of wheat straw lignin as revealed by analytical pyrolysis, 2D-NMR, and reductive cleavage methods. J Agric Food Chem. 2012;60:5922-35.

32. Ding SY, Liu YS, Zeng Y, Himmel ME, Baker JO, Bayer EA. How does plant cell wall nanoscale architecture correlate with enzymatic digestibility? Science. 2012;338:1055-60.

33. Liu T, Yang L, Liu B, Tan L. Hydroxycinnamic acids release during bioconversion of corn stover and their effects on lignocellulolytic enzymes. Bioresour Technol. 2019;294:122116.

34. Zhou Z, Lei F, Li P, Jiang J. Lignocellulosic biomass to biofuels and biochemicals: a comprehensive review with a focus on ethanol organosolv pretreatment technology. Biotechnol Bioeng. 2018;115:2683-702.

35. Alvira P, Tomas-Pejo E, Ballesteros M, Negro MJ. Pretreatment technologies for an efficient bioethanol production process based on enzymatic hydrolysis: a review. Bioresour Technol. 2010;101:4851-61.
36. Sun D, Sun SC, Wang B, Sun SF, Shi Q, Zheng L, Wang SF, Liu SJ, Li MF, Cao XF, et al. Effect of various pretreatments on improving cellulose enzymatic digestibility of tobacco stalk and the structural features of coproduced hemicelluloses. Bioresour Technol. 2020;297:122471.

37. Rocha GJM, Silva VFN, Martin C, Goncalves AR, Nascimento VM, SoutoMaior AM. Effect of xylan and lignin removal by hydrothermal pretreatment on enzymatic conversion of sugarcane bagasse cellulose for second generation ethanol production. Sugar Technol. 2013;15:390-8.

38. Gabhane J, William SPMP, Vaidya AN, Das S, Wate SR. Solar assisted alkali pretreatment of garden biomass: effects on lignocellulose degradation, enzymatic hydrolysis, crystallinity and ultra-structural changes in lignocellulose. Waste Manag. 2015;40:92-9.

39. Traore M, Kaal J, Martinez Cortizas A. Application of FTIR spectroscopy to the characterization of archeological wood. Spectrochim Acta A Molr Biomol Spectrosc. 2016;153:63-70.

40. He Y-C, Liu F, Gong L, Zhu Z-Z, Ding Y, Wang C, Xue Y-F, Rui H, Tao Z-C, Zhang D-P, Ma C-L. Significantly improving enzymatic saccharification of high crystallinity index's corn stover by combining ionic liquid [Bmim] $\mathrm{Cl}-\mathrm{HCl}$-water media with dilute $\mathrm{NaOH}$ pretreatment. Bioresour Technol. 2015;189:421-5.

41. Li P, Cai D, Luo Z, Qin P, Chen C, Wang Y, Zhang C, Wang Z, Tan T. Effect of acid pretreatment on different parts of corn stalk for second generation ethanol production. Bioresour Technol. 2016;206:86-92.

42. Karimi K, Taherzadeh MJ. A critical review of analytical methods in pretreatment of lignocelluloses: composition, imaging, and crystallinity. Bioresour Technol. 2016;200:1008-18.

43. Long L, Xu M, Shi Y, Lin Q, Wang J, Ding S. Characterization of two new Endo- $\beta$-1,4-xylanases from Eupenicillium parvum 4-14 and their applications for production of feruloylated oligosaccharides. Appl Biochem Biotechnol. 2018;186:816-33.

44. Zheng F, Huang JX, Yin YH, Ding SJ. A novel neutral xylanase with high SDS resistance from Volvariella volvacea: characterization and its synergistic hydrolysis of wheat bran with acetyl xylan esterase. J Ind Microbiol Biotechnol. 2013;40:1083-93.

45. Sluiter, Hames RR, Scarlata J, Templeton, Crocker. Determination of structural carbohydrates and lignin in biomass. In: National Renewable Energy Laboratory. 2012.

\section{Publisher's Note}

Springer Nature remains neutral with regard to jurisdictional claims in published maps and institutional affiliations.
Ready to submit your research? Choose BMC and benefit from:

- fast, convenient online submission

- thorough peer review by experienced researchers in your field

- rapid publication on acceptance

- support for research data, including large and complex data types

- gold Open Access which fosters wider collaboration and increased citations

- maximum visibility for your research: over 100M website views per year

At BMC, research is always in progress.

Learn more biomedcentral.com/submissions 